\title{
An insight into pharmacological and clinical basis of anti-IgE for add-on therapy of severe asthma
}

\author{
Girolamo Pelaia ${ }^{1}$ \\ Luca Gallelli2 \\ Maria Teresa Busceti ${ }^{1}$ \\ Alessandro Vatrella ${ }^{3}$ \\ Rosario Maselli ${ }^{1}$
}

\begin{abstract}
${ }^{1}$ Department of Medical and Surgical Sciences, University "Magna Græcia" of Catanzaro, Italy

2 Department of Health Science, University "Magna

Græcia" of Catanzaro, Italy

${ }^{3}$ Department of Medicine and Surgery, University

of Salerno, Italy
\end{abstract}

Address for correspondence:

Girolamo Pelaia, MD, FCCP

Campus Universitario "S. Venuta"

Viale Europa -Località Germaneto

88100 Catanzaro, Italy

Phone: + 3909613647302 - Fax + 3909613647193

E-mail: pelaia@unicz.it

\section{Summary}

IgE antibodies are crucially involved in mediating, maintaining and amplifying the allergic cascade. The humanized monoclonal anti-IgE antibody omalizumab is currently the only biologic drug approved for asthma treatment. Anti-IgE inhibits allergic responses by binding to serum $\lg E$, thus preventing their interactions with cellular IgE receptors. Omalizumab is also capable of down-regulating the expression of high affinity IgE receptors on inflammatory cells, as well as the numbers of eosinophils in both peripheral blood and induced sputum. Randomized clinical trials showed relevant clinical effects of omalizumab including improvements of respiratory symptoms and quality of life. Moreover, a marked reduction of asthma exacerbations, emergency room visits, and use of systemic corticosteroids and rescue bronchodilators was also observed. Omalizumab is relatively well tolerated, and only rarely induces anaphylactic reactions. Therefore, this drug represents a valid option as add-on therapy for most severe patients with persistent allergic asthma, inadequately controlled by high doses of standard treatments.

KEY WORDS: omalizumab, anti-lgE, severe asthma.
Introduction

It is well known that the propensity to develop exaggerated IgE responses to common environmental allergens, defined as atopy, plays a dominant role in the pathologic features and clinical manifestations of allergic asthma. Indeed, IgE antibodies are crucially involved in mediating, maintaining and amplifying the allergic cascade (1). Similar to the other antibody classes, the $\lg E$ structure consists of two variable antigenbinding fragments (Fab) and a receptor-binding constant portion $(\mathrm{Fc})$. In particular, the IgE molecule (molecular weight: $190 \mathrm{kD}$ ) comprises two identical light chains, each made of a variable $\left(\mathrm{V}_{\mathrm{L}}\right)$ and a constant domain $\left(\mathrm{C}_{\mathrm{L}}\right)$, as well as two identical heavy chains, each including a single-domain variable region $\left(\mathrm{V}_{\mathrm{H}}\right)$ and a constant region containing four domains (CE1, $\mathrm{C} \varepsilon 2, \mathrm{C} \varepsilon 3, \mathrm{C} \varepsilon 4)$. Each $\lg E$ antibody binds to its high affinity FceRI receptor, expressed as an $\alpha \beta \gamma_{2}$ tetramer on mast cells and basophils, and as an $\alpha \gamma_{2}$ trimer on human antigen-presenting cells (APCs), monocytes, eosinophils, platelets and smooth muscle cells (1). The IgE-binding function of FceRI is located within the two extracellular domains of its $\beta$ chain, which interact with the two $\mathrm{C} \varepsilon 3$ domains of $\operatorname{lgE}$, whereas the intracellular $\beta$ - and $\gamma$-chains are involved in signal transduction. In sensitized subjects, adjacent allergenic epitopes elicit the cross-linkage of two or more $\mathrm{IgE}$ molecules bound to their high affinity receptors (FceRI) on mast cell surface. Therefore, antigeninduced $\lg \mathrm{E}$ bridging promotes receptor aggregation and cell activation (2). As a consequence, mast cell degranulation and the subsequent release of preformed
Anti-lgE therapy was included in $2006 \mathrm{Gl}-$ NA guidelines, as add-on treatment to corticosteroids, LABA and other controller medications. granule-associated mediators

(histamine, tryptase, chymase and heparin) take place. In addition, newly formed eicosanoids (cysteinyl leukotrienes $\mathrm{C}_{4}-\mathrm{D}_{4}$ and prostaglandin $\mathrm{D}_{2}$ ) are secreted, as well as several different cytokines, chemokines and growth factors (IL-3, IL-4, IL-5, IL-6, IL-8, IL-13, RANTES, GM-CSF). These mechanisms are responsible for both early and late responses experienced by atopic asthmatic patients upon allergen exposure (3). The early-phase asthmatic response, which occurs within minutes of antigen binding to FceRI-bound IgE attached to the cell membrane, is due to airway smooth muscle contraction and mucus secretion induced by inflammatory mediators released from mast cells. The late-phase asthmatic response, usually occurring several hours after allergen inhalation, is char- 
acterized by bronchoconstriction and inflammatory changes mainly caused by cytokines and chemokines leading to eosinophil activation and recruitment within the airways.

Since the discovery of $\lg E$, made in 1967 by Ishizaka \& Ishizaka (4), these antibodies have been regarded as suitable targets for the development of anti-allergy treatments $(1,4,5)$. However, it has taken almost 40 years to translate such basic research finding into a therapeutic application available in medical practice. Indeed, anti-lgE therapy was included in 2006 within the step 5 of GINA (Global Initiative for Asthma) guidelines (6), as add-on treatment to inhaled and eventually oral corticosteroids, long-acting $\beta_{2}$-adrenergic agonists and other controller medications such as leukotriene modifiers and theophylline. After being introduced in Australia (2002) and United States (2003), utilization of the anti-lgE monoclonal antibody, omalizumab, was approved in 2005 also by the European Medicines Agency (EMA) as add-on therapy to improve asthma control in adult and adolescent patients (12 years of age and above) with severe persistent allergic asthma, who have an impaired lung function (forced expiratory volume in one second $<80 \%$ predicted) and experience frequent daytime symptoms and/or nocturnal awakenings, associated with multiple severe exacerbations despite daily high doses of inhaled corticosteroids and long-acting $\beta_{2}$-adrenoceptor agonists. More recently, the use of omalizumab has also been approved by EMA for children being at least 6 years old (7).

\section{Mechanism of action of omalizumab}

Omalizumab (molecular weight: $150 \mathrm{kD}$ ) is a recombinant humanized antibody comprising a human IgG framework which embeds the complementarity-determining region obtained from an anti-lgE antibody raised in mice (8). Consequently, only about $5 \%$ of the humanized monoclonal anti-IgE antibody includes residues of murine origin, and these structural features of course minimize the risk of developing an immune response towards the non-self protein (9). Omalizumab selectively binds with high affinity to the C\&3 domain of $\lg E$. In particular, any single IgE molecule has two antigenic sites for omalizumab, and can thus be bound by two drug molecules at the same time; similarly, one omalizumab molecule has two antigen-binding loci $\left(\mathrm{V}_{\mathrm{H}}-\mathrm{V}_{\mathrm{L}}\right.$ domains of $\lg \mathrm{G})$, and can thereby interact
IgE/omalizumab immune complexes remain and accumulate in either blood circulation or tissues nasal mucosa. such as airways and

with two IgE molecules at the same time (10). Therefore, binding of omalizumab to free $\lg E$ results in the formation of IgE/anti-IgE complexes, which can exist as trimers (molecular weight of about $500 \mathrm{kD}$ ) (Figure 1) or, less frequently, as examers (molecular weight of about $1000 \mathrm{kD}$ ) (11). The small dimensions of these biologically inert IgE/anti-lgE immune complexes signifi- cantly contribute to their safety. Indeed, IgE/omalizumab aggregates are soluble, do not bind complement and do not precipitate in the kidney, thus not causing immune complex-related diseases (12). These IgE/anti-lgE complexes are thus easily cleared from circulation by the reticuloendothelial system, through the interaction of their IgG component with the Fce receptors of the hepatic sinusoidal endothelial cells (11). IgE, as well as the IgG omalizumab, can freely cross capillaries thereby distributing between the vascular and the extravascular compartments. On the contrary, the IgE/omalizumab aggregates do not diffuse through capillary walls and are also characterized by a marked stability, due to the high affinity of omalizumab for $\lg E$. Because of these features, IgE/omalizumab immune complexes remain and accumulate where they are generated, namely in either blood circulation or local tissues such as airways and nasal mucosa (10).

The $\mathrm{C} \varepsilon 3$ domain of $\lg \mathrm{E}$ is the binding site shared by both high affinity FCERI and low affinity FceRII/CD23 receptors (13). FcERII receptors are expressed by $B$ lymphocytes, monocytes, eosinophils and epithelial cells, and upon IgE-induced activation they up-regulate IgE synthesis and facilitate B cell-operated antigen presentation to $T$ lymphocytes. Therefore, the interaction of omalizumab with IgE will prevent the latter from binding to both FcERI and FcERII/CD23 (10) expressed by several different cell types (Figure 1), thus interrupting the allergic cascade. This implies that omalizumab can interfere with the biological functions mediated by stimulation of both high-affinity and low-affinity lgE receptors. Blocking IgE binding to FceRI on mast cells and basophils inhibits allergen-induced degranulation, thus preventing histamine and tryptase release, and also affects lipid mediator production and cytokine/ chemokine gene expression. Moreover, blocking lgE binding to $\mathrm{Fc \varepsilon RI}$ receptors also reduces FceRI expression on basophils by approximately $97 \%$, which correlates with a decrease in responsiveness of basophils and mast cells to antigen challenge (9). It can thus be inferred that $\lg \mathrm{E}$ are able to up-regulate the synthesis of their own high-affinity receptors. Furthermore, binding of omalizumab to circulating $\lg E$ reduces their free serum levels by $96-99 \%$ (14). Omalizumab may also be able to suppress new IgE production, probably by inhibiting IgE interactions with the FcERII/CD23 receptors expressed on IgE-switched B cells; a further mechanism contributing to reduce IgE synthesis may be secondary to an omalizumab-dependent decrease in mast cell production of IgE-switching cytokines such as IL-4 and IL-13. In addition to binding omalizumab, $\mathrm{IgE}$ molecules comprised within the immune complexes formed with this drug can still bind allergens (at the $\mathrm{V}_{\mathrm{L}}-\mathrm{V}_{\mathrm{H}}$ domains), thereby neutralizing some of the antigenic stimuli (9). In fact, omalizumab-linked IgE antibodies cannot interact with their receptors anymore, thus potentially acting as protective agents against incoming allergens, which in such a way will be trapped and prevented from reaching residual FceRl-bound IgE on mast cells. Furthermore, by inhibiting IgE binding to FceRI receptors expressed on dendritic cells, omalizumab can reduce the efficiency of antigen pres- 


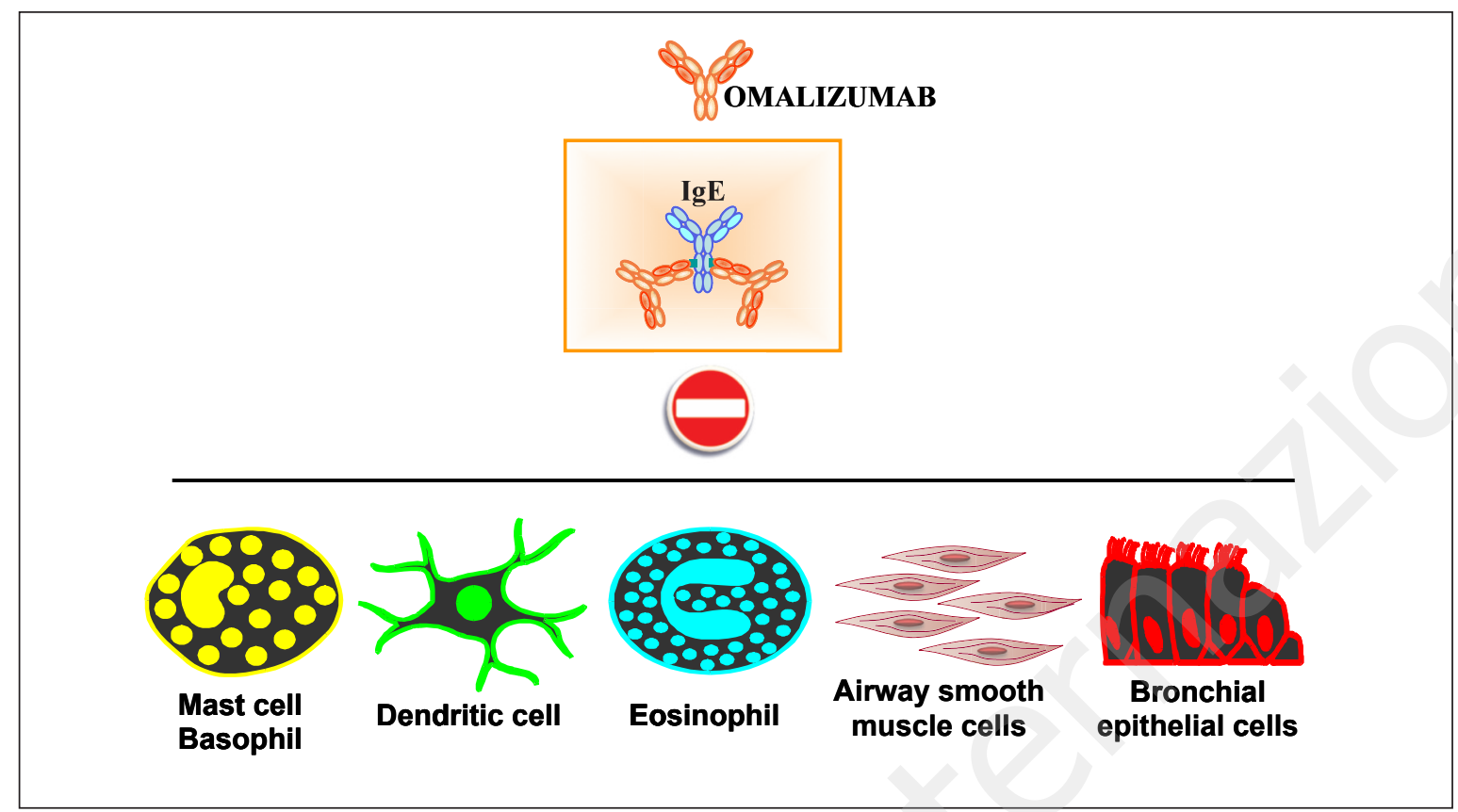

Figure 1 - Mechanism of action of omalizumab. Omalizumab binds to free $\lg \mathrm{E}$, thus forming immune complexes that prevent the interactions between $\mathrm{IgE}$ and their cellular receptors expressed by immune-inflammatory and airway structural cells including mast cells, basophils, eosinophils, dendritic cells, airway smooth muscle cells and bronchial epithelial cells. As a consequence, IgE-dependent bronchial inflammation and airway remodelling are inhibited.

entation to T lymphocytes. Omalizumab cannot bind to receptor-bound IgE and, consequently, it does not mimic the $\lg \mathrm{E}$ cross-linking induced by allergens, thus being largely non-anaphylactogenic in clinical use.

\section{Preclinical and clinical studies}

The efficacy of omalizumab and other similar antibodies has been evaluated in preclinical, both in vitro and in vivo studies. In particular, omalizumab inhibited IgE

binding to mast cells and sup-

$$
\begin{aligned}
& \text { The efficacy of oma- } \\
& \text { lizumab in adults, } \\
& \text { adolescents and chil- } \\
& \text { dren with moderate } \\
& \text { to severe asthma has } \\
& \text { been confirmed by a } \\
& \text { meta-analysis refer- } \\
& \text { ring to eight selected } \\
& \text { placebo-controlled } \\
& \text { studies, globally in- } \\
& \text { volving more than } \\
& 3,000 \text { patients. }
\end{aligned}
$$
pressed histamine release and airway smooth muscle contraction triggered by exposure of sensitized lung tissue to ovalbumin or ragweed antigen $(15,16)$. In cynomolgus monkeys, omalizumab induced a dose-dependent decrease in free serum IgE levels, and also prevented allergic skin reactions elicited by ragweed antigen (17). The first clini-

cal studies showed that, after nine weeks of treatment, omalizumab was able to inhibit both early and late asthmatic responses triggered by allergen inhalation (18). Since then, several multicenter, randomized, double-blind, and placebo-controlled phase III trials have been carried out in adoles- cents and adults with moderate to severe asthma (1924). Omalizumab has been given in addition to stable treatment with inhaled corticosteroids (ICS) and other anti-asthma drugs. Taking together these controlled studies showed that patients treated with omalizumab compared with placebo had fewer asthma exacerbations, improvements in asthma symptoms and quality of life, and decreased requirements for both ICS and rescue-bronchodilators (25-28). Moreover, the add-on therapy with omalizumab to uncontrolled severe asthmatics decreased hospitalizations, unscheduled outpatient visits and emergency room visits in comparison with placebo. Overall, patients who benefited most from omalizumab treatment were those with the poorest lung function, and receiving the highest ICS doses. Therefore, omalizumab exerted its greatest effects in most severe asthma phenotypes, thus being particularly useful as an add-on treatment option for patients whose disease was not well controlled.

In particular, the Busse trial included patients with severe allergic asthma, whose disease exacerbations were significantly decreased by omalizumab during two study phases, including ICS treatments with stable or reduced doses, respectively (19); with respect to the placebo group, in addition, a higher percentage of patients receiving omalizumab were able to reduce ICS intake. These findings were also confirmed by Solér et al. and Holgate et al., who enrolled subjects with moderate-to-severe allergic asthma whose symptoms were not well controlled by regular therapy with $\operatorname{ICS}(20,21)$. The SOLAR (Study of Omalizumab in comorbid Asth- 
ma and Rhinitis) study was designed to test the effects of omalizumab on concomitant allergic asthma and rhinitis (22). During a 28-week treatment with omalizumab, both adolescents and adults with moderate-tosevere asthma and moderate-to-severe persistent rhinitis were investigated. Omalizumab elicited significant improvements in the quality of life related to both asthma and rhinitis, assessed by AQLQ (Asthma Quality-of-Life Questionnaire) and RQLQ (Rhinitis Qualityof-Life Questionnaire) questionnaires, respectively. These results are very interesting because of the frequent association between asthma and rhinitis, two allergic diseases linked by reciprocal pathogenic connections.

One of the most important studies aimed to evaluate the clinical effects of omalizumab has been the INNOVATE (Investigation of Omalizumab in Severe Asthma Treatment) trial (24). This study, referring to 419 allergic patients with severe persistent asthma, whose age ranged from 12 to 75 years, involved 108 centers located in 14 countries. Participating subjects had decreased lung function ( $F E V_{1} \geq 40-<80 \%$ predicted at randomization), associated with a recent history of clinically significant exacerbations. In particular, patients had experienced an average of 2.1 exacerbations per year, and $67 \%$ of them were considered to be at risk of asthma-related mortality, assessed on the basis of emergency room visits, hospitalizations or intubations occurred in the past year. Symptom control was not satisfactory, despite a stable inhaled therapy with relatively high doses of corticosteroids and long-acting $\beta_{2-}$ adrenoceptor agonists. In addition, an average of 31 school/work days had been missed in the past year. Following an 8-week run-in phase, patients were double-blindly randomized to receive for 28 weeks either omalizumab or placebo as add-on treatment to GINA step 4 therapy. INNOVATE results showed that, when compared to placebo (210 patients), omalizumab (209 patients) induced significant decreases in the total numbers of emergency visits as well as in the rates of both severe and clinically relevant asthma exacerbations, requiring unscheduled systemic corticosteroids. Omalizumab also elicited a clinically meaningful improvement in quality of life, evaluated by the AQLQ questionnaire ( $>0.5$ points). Furthermore, in comparison with placebo, omalizumab produced significant improvements in both asthma symptom score and peak expiratory flow (PEF). Treatment with omalizumab was globally considered to be more effective than placebo by both patients and investigating physicians.

The efficacy of omalizumab in adults, adolescents and children with moderate to severe asthma has been further confirmed by a recent meta-analysis referring to eight selected placebo-controlled studies, published between 2001 and 2009 and globally involving more than 3,000 patients (29). In particular, this systematic review considered as primary outcomes the reduction of steroid use and asthma exacerbations; secondary outcome measures included lung function, rescue medication use, asthma symptoms and health-related quality of life. Two further recent placebo-controlled trials have confirmed the efficacy of omalizumab. In the first one, including 850 patients aged 12-75 years, Hanania et al. showed that, when compared with placebo, 48 weeks of treatment with omalizumab significantly decreased asthma symptoms and exacerbations, as well as the mean daily number of albuterol puffs (30). Moreover, Busse et al. have recently shown in 419 inner city children, adolescents and young adults with persistent allergic, moderate-to-severe asthma, that addition of omalizumab to guidelinebased therapy for 60 weeks further improved asthma control, nearly eliminated seasonal peaks in exacerbations, and also reduced the need for inhaled corticosteroids (31). Moreover, the globally favourable pharmacodynamic pattern of omalizumab has also been corroborated by several phase IV, post-marketing surveillance trials referring to patients affected by severe persistent allergic asthma, treated with omalizumab for 5-12 months in real-life practice in France, Germany, Belgium, Italy and Greece (32-38).

We think that in order to optimize the therapeutic responses to omalizumab, it is critical to carefully select the asthmatic phenotypes more likely to be susceptible to anti-IgE treatment. In our experience, during add-on therapy with omalizumab, the best results can be obtained in allergic subjects with severe, uncontrolled and oral steroid-dependent asthma, characterized by the exacerbation-prone phenotype. In these patients, we have observed dramatic reductions in exacerbation rate and oral corticosteroid intake, associated with a significant improvement in lung function $\left(F E V_{1}\right.$ and $\mathrm{FEV}_{1} / \mathrm{FVC}$ ratio) and a relevant decrease of peripheral blood eosinophils (39). In order to predict the therapeutic response to omalizumab in allergic asthmatic patients, the EXTRA study has recently shown that elevated concentrations of biomarkers of Th2 inflammation, such as exhaled nitric oxide, peripheral blood eosinophils and serum periostin are associated, with respect to asthmatic individuals not displaying high levels of these biomarkers, with a significant greater reduction in asthma exacerbation frequency (40).

In addition to effectively reducing allergic bronchial inflammation, omalizumab can also affect airway remodelling, which is a key feature of severe asthma. Indeed, it is notable that airway structural cells such as bronchial epithelial cells and airway smooth muscle cells express on their surface high-affinity IgE receptors $(41,42)$ (Figure 1$)$. These IgE receptors can be involved in the production of growth factors which have a central role in airway remodelling events, that prominently occur in patients with the most severe disease phenotypes. Therefore, omalizumab could potentially interfere with the synthetic activity of bronchial epithelium. Indeed, omalizumab decreases the production of transforming growth factor- $\beta$ (TGF- $\beta$ ) in a cellular model of allergic asthma (43), suggesting that this drug could thus inhibit the fibrotic effects exerted by TGF- $\beta$ in asthmatic airways. Furthermore, it has been recently reported that omalizumab can significantly decrease the concentration of endothelin-1 (ET-1) - a peptide involved in the pathogenesis of airway structural changes such as subepithelial fibrosis and proliferation of bronchial smooth muscle cells - in the exhaled 
breath condensate of patients with severe persistent allergic asthma (44). On the other hand, pre-treatment with omalizumab of airway smooth muscle cells obtained from allergic asthmatic patients significantly decreased IgE-dependent production of extracellular matrix proteins such as collagen type I, collagen type III and fibronectin (45). Recent preliminary findings, obtained in a limited number of asthmatic patients by means of computed tomography (CT) imaging, have shown that omalizumab reduced airway wall thickness and increased the bronchial luminal area (46). These findings have been recently corroborated by histopathological observations referring to bronchial biopsy samples obtained from patients with severe persistent allergic asthma before and 12 months after treatment with omalizumab, showing a significant reduction in the thickness of epithelial reticular basement membrane (47).

Very recent reports suggest that omalizumab, in addition to being very effective for the treatment of allergic asthma, can be also useful in the management of apparently non-allergic phenotypes of this airway disease. Indeed, a 2-year treatment with omalizumab of 29 patients with non-allergic asthma elicited a better disease control (48). Furthermore, a real-life study performed in a large group of asthmatics also including about 60 non-allergic subjects, showed that omalizumab strongly reduced hospitalizations and emergency department visits in such patients, and these results were very similar to those detected in the greater percentage of enrolled allergic individuals (38). Moreover, the first randomized, controlled trial specifically assessing the effects of omalizumab in patients with nonallergic asthma, demonstrated that, when compared to placebo, omalizumab was able to elicit a trend towards a decreased exacerbation frequency, as well as to induce an overall increase in $\mathrm{FEV}_{1}$ and a significant reduction in FceRI expression on basophils and plasmacytoid dendritic cells (49). These therapeutic benefits experienced by non-allergic asthmatic patients undergoing add-on treatment with omalizumab could be explained according to at least two speculative hypotheses (50). Firstly, asthmatic patients who are defined as "non-allergic" on the basis of skin prick tests and serum levels of specific lgE antibodies, could in fact be allergic to an unrecognized allergen, in the context of a local allergic reaction taking place within the airways. Alternatively, omalizumab might disrupt the tight interactions linking innate and adaptive immune responses, and in such a context a key role could be played by the effects exerted by this drug on plasmacytoid dendritic cells. In particular, the omalizumab-dependent decreased amount of circulating free $\operatorname{lgE}$, paralleled by a reduced expression of high affinity lgE receptors, can probably strengthen the anti-viral immune responses mediated by dendritic cells, thus preventing asthma exacerbations which are often caused by viral infections; in other words, omalizumab could contribute to restore the impaired anti-viral functions of dendritic cells, possibly suppressed by an enhanced IgE-mediated cross-linking of $\mathrm{FcERI}$ occurring on the surface of these cells (50).

\section{Safety}

Overall, omalizumab is well tolerated and the most frequent adverse events are local reactions at the level of injection sites, usually manifesting as warmth, erythema, swelling, bruising, and sometimes as urticaria-like eruptions. Other relatively frequent adverse effects include headache, fatigue and nausea. The pivotal phase III clinical trials have shown that the frequencies of adverse events were similar between omalizumab and control groups; the majority of unwanted side effects were of short duration and mildly to moderately severe (51). Such a side-effect pattern has also been confirmed in long-term follow-up studies $(32,35)$. Although omalizumab is considered to be a non-anaphylactogenic antibody, anaphylactic and anaphylactoid reactions have been sporadically reported. In a publication that reviewed data referring to anaphylaxis and anaphylactoid reactions reported by phase III clinical trials and post-marketing surveillance studies, it was noted that among 39,510 patients receiving omalizumab, 35 subjects manifested 41 episodes of anaphylaxis associated with omalizumab administration, corresponding to an anaphylaxis-reporting rate of $0.09 \%$ of patients (52). All patients responded to anti-anaphylactic treatments, and there were no fatalities or respiratory failures requiring intubation. A major concern arose from the small increase in the numbers of malignancies including tumours of breast, prostate, parotid, and a case of lymphoma, detected in initial studies of omalizumab-treated patients compared with control groups (53). However, no difference in cancer incidence was found between subjects undergoing omalizumab therapy and the general population (54). Some sporadic cases of Churg-Strauss syndrome possibly related to omalizumab treatment have been reported (55-57). However, similarly to previous observations regarding the use of leukotriene receptor antagonists (58), it is not yet clear whether these drugs or omalizumab may cause Churg-Strauss syndrome, or simply unmask a pre-existing latent disease because they facilitate corticosteroid tapering and withdrawal.

Given the role played by $\lg E$ in immune defense against parasitic infestation, the risk of developing such infections could be associated with the use of anti-IgE therapies. However, evolutionary theories suggest that although IgE are very important in protecting animals and even humans living in primitive habitats, these antibodies seem to have become non- essential in many regions of the world characterized by relatively clean household and community environments. On the other hand, according to the results of a study carried out in allergic subjects resident in poor urban areas of Brazil and at high risk of helminthic infections, omalizumab appeared to be effective and safe, although its use was associated with a slightly increased risk of parasitic infections (59). Therefore, caution should be recommended in the use of omalizumab by patients at high risk of helminthic infections, particularly when living in or travelling to areas where these infections are endemic. In case of unsatisfactory re- 
sponses to conventional antihelminthic treatments, discontinuation of omalizumab should be considered. More recently, some concerns have been raised by FDA about the potential occurrence in patients treated with omalizumab, when compared with subjects not receiving this drug, of cardiovascular and cerebrovascular adverse effects (60). Anyway, FDA is not recommending any changes to the prescribing information for omalizumab, and is not advising patients to stop taking this drug. In particular, because it has been hypothesized that omalizumab could induce an increase in ischemic heart disease, arrhythmias, cardiac failure, pulmonary hypertension and thrombotic events, an ongoing observational study (EXCELS) is evaluating the long-term safety profile of omalizumab in patients followed for 5 years. However, a recent systematic analysis of eight selected, placebo-controlled trials collectively referring to 3,429 participants has not detected any indication of an increased cardiovascular risk due to the use of omalizumab (29). On the contrary, four cases of adverse cardiovascular effects, including angina pectoris, tachyarrhytmia, and atrial fibrillation were reported in the placebo groups. Moreover, a case of cardiac arrest also occurred in the placebo group.

Preliminary studies including small numbers of women who have received omalizumab during pregnancy have not detected any significant difference in comparison with control groups with regard to normal deliveries and spontaneous abortion rates (61).

Therefore, the current consensus among clinicians is that the use of omalizumab is safe. However, as with any relatively new class of drugs, continued surveillance is needed as its utilization in real life practice continues to grow, thus involving progressively increasing numbers of patients (62).

\section{Concluding remarks}

Add-on treatment with omalizumab may improves disease control in severe atopic patients experiencing persistent respiratory symptoms and high exacerbation rate in spite of an optimized standard therapy (63). Omalizumab efficacy in reducing allergic airway inflammation and its clinical manifestations has been shown by several different controlled trials, also including many real-life studies. The safety profile of the drug is quite good, with the exception of few, sporadically reported relevant side effects.

Furthermore, some recent developments regarding add-on treatment with omalizumab mainly refer to its potential effects on airway remodelling and non-allergic asthma. Indeed, given the wide expression of $\mathrm{IgE}$ receptors not only on cross-talking immune/inflammatory cells, but also on airway structural cells including bronchial epithelial cells and airway smooth muscle cells (Figure 1), it will be very interesting to further explore the promising anti-remodelling effects of omalizumab, thus hoping that anti-lgE therapy could eventually prevent and/or attenuate the progressive decline in respiratory function, thereby possibly affecting the natural history of severe asthma. Another exciting scenario is provided by the potential use of omalizumab also for the add-on treatment of non-allergic asthma. Of course, the suggestive recent evidence coming out in this regard not only from occasional reports, but especially from well-structured trials, needs to be confirmed by future, urgently needed studies.

\section{References}

1. Gould HJ, Sutton BJ. IgE in allergy and asthma today. Nature Reviews Immunology 2008;8(3): 205217.

2. Galli SJ, Tsai M, Piliponsky AM. The development of allergic inflammation. Nature 2008;454(7203): 445-454.

3. Holgate ST. Pathogenesis of asthma. Clinical Experimental Allergy 2008;38(6):872-897.

4. Ishizaka K, Ishizaka T. Identification of $y E$ antibodies as a carrier of reaginic activity. Journal of Immunology 1967;99(6):1187-1198.

5. Pelaia G, Vatrella A, Calabrese C, Mazzarella G, Marsico SA. New perspectives in asthma treatment. Allergy 2000;55 Suppl. 61:60-66.

6. Global Initiative for Asthma (GINA), "Global strategy for asthma management and prevention", Available from: http://www.ginasthma.org, (accessed: November 15, 2013).

7. European Public Assessment Report (Xolair), Available from: http://www.ema.europa.eu/humandocs/ PDFs/EPAR/Xolair/emea-combined-h606en.pdf (accessed: November 15, 2013).

8. Presta LG, Lahr SJ, Shields RL, et al. Humanization of an antibody directed against IgE. Journal of Immunology 1993;151(5):2623-2632.

9. Spector S. Omalizumab efficacy in allergic disease. Panminerva Medica 2004;46(2):141-148.

10. Chang TW, Wu PC, Hsu CL, Hung AF. Anti-IgE antibodies for the treatment of IgE-mediated allergic diseases. Advances in Immunology 2007;93:63-119.

11. Hochhaus G, Brookman L, Fox H, et al. Pharmacodynamics of omalizumab: implications for optimised dosing strategy and clinical efficacy in the treatment of allergic asthma. Current Medical Research Opinion 2003;19(6):491-498.

12. Fox JA, Hotaling TE, Struble C, Ruppel J, Bates DJ, Schoenhoff MB. Tissue distribution and complex generation with IgE of an anti-lgE antibody after intravenous administration in cynomolgus monkeys. Journal of Pharmacology and Experimental Therapeutics 1996;279(2):1000-1008.

13. Presta L, Shields R, O' Connell L,et al. The binding site of a human immunoglobulin $E$ for its high affinity receptor. Journal of Biological Chemistry 1994;269(42):26368-26373.

14. Holgate S, Casale T, Wenzel S, Bousquet J, Deniz $\mathrm{Y}$, Reisner C. The anti-inflammatory effects of omalizumab confirm the central role of IgE in allergic inflammation. Journal of Allergy and Clinical Immunology 2005;115(3):459-465. 
15. Shields RL, Whether WR, Zioncheck K, et al. Inhibition of allergic reactions with antibodies to IgE. International Archives of Allergy and Immunology 1995;107(1-3):308-312.

16. Haak-Frendscho M, Saban R, Shields RL, Jardieu PM. Anti-immunoglobulin E antibody treatment blocks histamine release and tissue contraction in sensitized mice. Immunology 1998;94(1):115-121.

17. Schulman ES. Development of a monoclonal antiimmunoglobulin $\mathrm{E}$ antibody (omalizumab) for the treatment of allergic respiratory disorders. American Journal of Respiratory and Critical Care Medicine 2001;164(8) (Pt. 2):S6-S11.

18. Fahy JV, Fleming HE, Wong $\mathrm{HH}$, et al. The effect of an anti-IgE monoclonal antibody on the early- and late-phase responses to allergen inhalation in asthmatic subjects. American Journal of Respiratory and Critical Care Medicine 1997;155(6):1828-1834.

19. Busse W, Corren J, Lanier BQ, et al. Omalizumab, anti-IgE recombinant humanized monoclonal antibody for the treatment of severe allergic asthma. Journal of Allergy and Clinical Immunology 2001;108(2):184-190.

20. Solér M, Matz J, Townley R, et al. The anti-lgE antibody omalizumab reduces exacerbations and steroid requirement in allergic asthmatics. European Respiratory Journal 2001;18(2):254-261.

21. Holgate ST, Chuchalin AG, Hebert J, et al. Efficacy and tolerability of a recombinant anti-immunoglobulin $\mathrm{E}$ antibody (omalizumab) in severe allergic asthma. Clinical and Experimental Allergy 2004; 34(4):632-638.

22. Vignola AM, Humbert M, Bousquet J, et al. Efficacy and tolerability of anti-immunoglobulin $E$ therapy with omalizumab in patients with concomitant allergic asthma and persistent allergic rhinitis: SOLAR. Allergy $2004 ; 59(7): 709-717$.

23. Ayres JG, Higgins B, Chilvers ER, Ayre G, Blogg M, Fox $\mathrm{H}$. Efficacy and tolerability of anti-immunoglobulin $\mathrm{E}$ therapy with omalizumab in patients with poorly controlled (moderate-to-severe) allergic asthma. Allergy 2004;59(7):701-708.

24. Humbert M, Beasley R, Ayres J, et al. Benefits of omalizumab as add-on therapy in patients with severe persistent asthma who are inadequately controlled despite best available therapy (GINA 2002 step 4 treatment): INNOVATE. Allergy 2005;60(3) :309-316.

25. Price $D$. The use of omalizumab in asthma. Primary Care Respiratory Journal 2008;17(2):62-72.

26. Pelaia G, Renda T, Romeo P, Busceti MT, Maselli R. Omalizumab in the treatment of severe asthma: efficacy and current problems. Therapeutic Advances in Respiratory Research 2008;2(6):409421.

27. D'Amato G. Treating moderate-to-severe allergic asthma with anti-lgE monoclonal antibody (omalizumab). An update. European Annals of Allergy and Clinical Immunology 2010;42(4):135-140.

28. Pelaia G, Gallelli L, Renda T, et al. Update on optimal use of omalizumab in management of asthma Journal of Asthma and Allergy 2011;4:49-59.
29. Rodrigo GJ, Neffen H, Castro-Rodriguez JA. Efficacy and safety of subcutaneous omalizumab vs placebo as add-on therapy to corticosteroids for children and adults with asthma: a systematic review. Chest 2011;139(1):28-35

30. Hanania NA, Alpan O, Hamilos DL, et al. Omalizumab in severe allergic asthma inadequately controlled with standard therapy: a randomized trial. Annals of Internal Medicine 2011;154(9):573-582.

31. Busse WW, Morgan WJ, Gergen PJ, et al. Randomized trial of omalizumab (anti-IgE) for asthma in inner-city children. New England Journal of Medicine 2011;364(11):1005-1015.

32. Molimard M, de Blay F, Didier A, Le Gros V. Effectiveness of omalizumab (Xolair) in the first patients treated in real-life practice in France. Respiratory Medicine 2008;102(1):71-76.

33. Korn S, Thielen A, Seyfried S, Taube C, Kornmann O, Buhl R. Omalizumab in patients with severe persistent allergic asthma in a real-life setting in Germany. Respiratory Medicine 2009;103(11):17251731.

34. Brusselle G, Michils A, Louis R, et al. Real-life effectiveness of omalizumab in patients with severe persistent allergic asthma: The PERSIST study. Respiratory Medicine 2009;103(11):1633-1642.

35. Cazzola M, Camiciottoli G, Bonavia M, et al. Italian real-life experience of omalizumab. Respiratory Medicine 2010;104(10):1410-1416.

36. Molimard M, Buhl R, Niven R, et al. Omalizumab reduces oral corticosteroid use in patients with severe allergic asthma; Real-life data. Respiratory Medicine 2010;104(9):1381-1385.

37. Tzortzaki EG, Georgiou A, Kampas D, et al. Longterm omalizumab treatment in severe allergic asthma: the South-Eastern Mediterranean "reallife" experience. Pulmonary Pharmacology \& Therapeutics 2012;25(1):77-82.

38. Grimaldi-Bensouda L, Zureik M, Aubier M, et al. Does omalizumab make a difference to the real-life treatment of asthma exacerbations? Results from a large cohort of patients with severe uncontrolled asthma. Chest 2013;143(2):398-405.

39. Pelaia G, Gallelli L, Romeo P, et al. Omalizumab decreases exacerbation frequency, oral intake of corticosteroids and peripheral blood eosinophils in atopic patients with uncontrolled asthma. International Journal of Clinical Pharmacology and Therapeutics 2011;49(12):713-721.

40. Hanania NA, Wenzel S, Rosén K, et al. Exploring the effects of omalizumab in allergic asthma: an analysis of biomarkers in the EXTRA study. American Journal of Respiratory and Critical Care Medicine 2013;187(8):804-811.

41. Campbell AM, Vachier I, Chanez P, et al. Expression of the high-affinity receptor for IgE on bronchial epithelial cells of asthmatics. American Journal of Respiratory Cell and Molecular Biology 1998;19(1): 92-97.

42. Redhu NS, Gounni AS. The high affinity IgE receptor (FceRI) expression and function in airway smooth muscle. Pulmonary Pharmacology \& Ther- 
apeutics 2013;26(1):86-94.

43. Huang YC, Leyko B, Frier M. Effects of omalizumab and budesonide on markers of inflammation in human bronchial epithelial cells. Annals of Allergy and Asthma Immunology 2005;95(5):443-451.

44. Zietkowski Z, Skiepko R, Tomasiak-Lozowska MM, Bodzenta-Lukaszyk A. Anti-IgE therapy with omalizumab decreases endothelin-1 in exhaled breath condensate of patients with severe persistent allergic asthma. Respiration 2010;80(6):534-542.

45. Roth M, Zhong J, Zumkeller C, S'ng CT, Goulet S, Tamm M. The role of IgE-receptors in IgE-dependent airway smooth muscle cell remodelling. PLOS ONE 2013;8(2):e56015.

46. Hoshino M, Ohtawa J. Effects of adding omalizumab, an anti-immunoglobulin $\mathrm{E}$ antibody, on airway wall thickening in asthma. Respiration 2012; 83(6):520-528.

47. Riccio AM, Dal Negro RW, Micheletto C, et al. Omalizumab modulates bronchial reticular basement membrane thickness and eosinophil infiltration in severe persistent allergic asthma patients. International Journal of Immunopathology and Pharmacology 2012;25(2):475-484.

48. de Llano LP, Vennera Mdel C, Alvarez FJ, et al. Effects of omalizumab in non-atopic asthma: results from a Spanish multicenter registry. Journal of Asthma 2013;50(3):296-301.

49. Garcia G, Magnan A, Chiron R, et al. A proof of concept randomized-controlled trial of omalizumab in patients with severe difficult to control nonatopic asthma. Chest 2013;144(2):411-419.

50. Lommatzsch M, Korn S, Buhl R, Virchow JC. Against all odds: anti-IgE for intrinsic asthma?. Thorax 2013, in press.

51. Holgate ST, Djukanovich R, Casale T, Bousquet J. Anti-immunoglobulin $\mathrm{E}$ treatment with omalizumab in allergic diseases: an update on anti-inflammatory activity and clinical efficacy. Clinical and Experimental Allergy 2005;35(4):408-416.

52. Cox L, Platts-Mills TAE, Finegold I, Schwartz LB, Simons FER, Wallace DV. American Academy of Al- lergy, Asthma and Immunology/American College of Allergy, Asthma and Immunology Joint Task Force report on omalizumab-associated anaphylaxis. Journal of Allergy and Clinical Immunology 2007;120(6):1373-1377.

53. Miller CWT, Krishnaswamy N, Johnston C, Krishnaswamy G. Severe asthma and the omalizumab option. Clinical and Molecular Allergy 2008;6:4.

54. Busse W, Buhl R, Fernandez Vidaurre C, et al. Omalizumab and the risk of malignancy: results from a pooled analysis. Journal of Allergy and Clinical Immunology 2012;129(4):983-989.

55. Winchester DE, Jacob A, Murphy T. Omalizumab for asthma. New England Journal of Medicine 2006; 355(12):1281-1282.

56. Puéchal X, Rivereau P, Vinchon F. Churg-Strauss syndrome associated with omalizumab. European Journal of Internal Medicine 2008;19(5):364-366.

57. Bargagli E, Madioni C, Olivieri C, Penza F, Rottoli P. Churg-Strauss vasculitis in a patient treated with omalizumab. Journal of Asthma 2008;45(2):115116.

58. McDanel DL, Muller BA. The linkage between Churg-Strauss syndrome and leukotriene receptor antagonists: fact or fiction?. Therapeutics and Clinical Risk Management 2005;1(2):125-140.

59. Cruz AA, Lima F, Sarinho E, et al. Safety of anti-immunoglobulin $E$ therapy with omalizumab in allergic patients at risk of geohelminth infections. Clinical and Experimental Allergy 2007;37(2):197-207.

60. U.S. Food and Drug Adminisration. Early communication about an ongoing safety review of omalizumab (marketed as Xolair), June 16, 2009.

61. Corren J, Casale TB, Lanier B, Buhl R, Holgate S, Jimenez P. Safety and tolerability of omalizumab. Clinical and Experimental Allergy 2009;39(6):788797.

62. Tan RA, Corren J. Safety of omalizumab in asthma. Expert Opinion on Drug Safety 2011;10(3):463-471.

63. Pelaia G, Vatrella A, Maselli R. The potential of biologics for the treatment of asthma. Nature Reviews Drug Discovery 2012;11(12):958-972. 